\title{
O massacre dos "Nativos" do Arapuim na luta pelo reconhecimento do território quilombola no norte de Minas Gerais'
}

The massacre of the "Natives" of the Arapuim in the fight for the recognition of the quilombola territory in the north of Minas Gerais

\section{Greiciele Soares da Silva}

Brasil. Universidade Estadual de Montes Claros. Doutoranda no Programa de Pós-Graduação em Desenvolvimento Social - PPGDS / UNIMONTES. Mestre em Sociedade, Ambiente e Território pela UFMG. Bacharel em Ciências Sociais pela Universidade Estadual de Montes Claros. ID ORCID: https://orcid.org/0000-0002-0841-3593.E-mail: greicytstsoares123@gmail.com. Colaboração: Pesquisa bibliográfica; Pesquisa empírica; Análise de dados; Redação.

\section{Rômulo Soares Barbosa}

Brasil. Universidade Estadual de Montes Claros. Professor-Doutor no Programa de Pós-Graduação em Desenvolvimento Social - PPGDS / Universidade Estadual de Montes Claros - Unimontes. ID ORCID: https://orcid.org/0000-0001-9226-2312.E-mail: romulosoaresbarbosa@gmail.com. Colaboração: Análise de dados; Redação.

O uso do termo "Nativos" não é uma construção teórica do presente estudo, é uma apropriação do termo utilizado pelos próprios sujeitos do grupo social estudado, enquanto forma de identificação e diferenciação. O termo "Nativos" é entendido aqui como uma identidade local, reconhecida entre si pelos integrantes do grupo social, bem como por comunitários de outros grupos da região. É importante considerar que o uso "Nativos do Arapuim" é uma apropriação dessa construção social identitária com grande significado para seu grupo social, que busca enfatizar o pertencimento deles ao local, às margens do rio Arapuim, que separa os municípios de Verdelândia e São João da Ponte no Norte de Minas Gerais. Sendo assim, utilizaremos ao longo do debate o nome social do grupo, reconhecendo a sua construção identitária para o mesmo. 


\section{Resumo}

Este trabalho busca discutir o processo de violação dos direitos e a busca por justiça vivenciada pela comunidade dos Nativos do Arapuim, no município de Verdelândia no Norte de Minas Gerais. Uma das estratégias de luta é o acionamento da identidade quilombola, que representa uma categoria analítica e jurídica, permitindo aos Nativos estabelecer um diálogo com o Estado, tendo como finalidade a garantia e legitimação de seus direitos. O grupo social dos Nativos do Arapuim é formado por pessoas descendentes dos posseiros e camponeses que foram expulsos e desterritorializados nos anos de 1960, no emblemático conflito conhecido como "Massacre de Cachoeirinha", ocorrido no antigo povoado de Cachoeirinha, e que atualmente é o município de Verdelândia. Este trabalho apresentado é resultado da pesquisa e construção do projeto de dissertação de mestrado, e para o desenvolvimento de tal estudo, foram realizados os seguintes procedimentos metodológicos: trabalho de campo com observação direta e entrevistas com lideranças políticas da comunidade, revisão bibliográfica e pesquisa documental.

Palavras-chave: Direito, Identidade, Luta por Território, Quilombola.

\section{Abstract}

This paper discusses the process of rights violation and the search for justice experienced by the Arapuim Natives from the municipality of Verdelândia in northern Minas Gerais. One of their resistance strategies is the reference to the Quilombola identity, which represents an analytical and legal category, allowing them to dialogue with the State with the purpose of guaranteeing and legitimizing their rights. This social group is formed by people descended from squatters and peasants who were expelled and deterritorialized in the '60s during the emblematic conflict known as Massacre de Cachoeirinha, which occurred in the former village of Cachoeirinha, current Verdelândia. This paper is the result of the research and construction of a masters' dissertation project, wherein the following methodological procedures were performed: field work with direct observation, and interviews with political leaderships of the social group analyzed, bibliographic review and documentary research.

Keywords: Law, Identity, Fight for Territory, Quilombola. 


\section{INTRODUÇÃO}

Os processos de lutas sociais representam as demandas por garantia de direitos. No caso dos povos e comunidades tradicionais, muitas das demandas incluem denúncias acerca de práticas e atos de violação de direitos básicos. Os atos de agressões simbólicas e físicas são recorrentes no caso de disputa por território. Os quilombolas Nativos do Arapuim vivenciam essa realidade em que a busca pelos direitos será legitimada pelo reconhecimento do seu território. Esse grupo social se autodenomina Nativos do Arapuim como forma de diferenciação aos demais grupos e de apresentar seu pertencimento à região do rio Arapuim, uma demarcação natural entre os municípios de Verdelândia e São João da Ponte.

O grupo tem vínculo de parentesco com os posseiros expropriados na década de 1960 no conflito de Cachoeirinha. Após o conflito, o povoado se torna município, sendo emancipado no ano de 1995, guardando em seu histórico o processo de luta e violência sofrida pelos camponeses da época. No caso dos Nativos do Arapuim, a luta se apoia no acionamento da identidade e na constituição dos modos de vida tradicional, previstos no Decreto Federal $\mathrm{n}^{\circ} 6040$ de fevereiro de $2007^{2}$, Decreto Federal no 4.887, de 20 de novembro de $2003^{3}$ e no Art. 68 do Ato das Disposições Constitucionais Transitórias ADCT da Constituição Federal de 1988.

A denominação do grupo pode ser entendida pela fala "Nativos do Arapuim é porque nós nascemos aqui" ${ }^{4}$, e reforçam ainda sobre a região Arapuim “é porque é um rio, esse rio que passa aqui, então, as comunidades nativas do Arapuim, nativas do Arapuim porque moravam nas margens do rio Arapuim, os antepassados moravam aí" ${ }^{5}$. O massacre de Cachoeirinha fez que

\footnotetext{
"Institui a Política Nacional de Desenvolvimento Sustentável dos Povos e Comunidades Tradicionais PNPCT".

3 "Regulamenta o procedimento para identificação, reconhecimento, delimitação, demarcação e titulação das terras ocupadas por remanescentes das comunidades dos quilombos de que trata o art. 68 do Ato das Disposições Constitucionais Transitórias".

4 Entrevistado 3. Nativo do Arapuim. Entrevista realizada 28/02/17. Pesquisa de Mestrado (SILVA, 2017).

5 Entrevistado 3. Nativo do Arapuim. Entrevista realizada 28/02/17. Pesquisa de Mestrado (SILVA, 2017).
} 
os moradores do local se espalhassem pelas áreas, buscando local seguro para permanência das famílias, o que possibilitou a formação de novas comunidades em torno do rio Arapuim e fazendo que os membros da associação quilombola residam em locais diferentes, como comunidades rurais em que possuem grau de parentescos.

Consideramos que a luta por terra e território vivenciada pelos grupos sociais do município de Verdelândia se inicia na década de 1960 com o "Massacre de Cachoeirinha" ${ }^{6}$. É importante ressaltar que antes desse período temos todo um contexto de privação da terra, seja pela geração de posseiros descendentes de escravos, ou por migrantes de outras regiões que também sofreram expropriações. O recorte que evidenciamos é a década de 1960, discutido como retomada histórica para auxiliar na compreensão do contexto de luta.

No caso particular dos Nativos do Arapuim, descendentes dos posseiros da antiga Cachoeirinha, reforçamos que o início efetivo da luta é no ano de 2004, quando a identidade camponesa é acionada pelo grupo, a herança histórica de luta é reafirmada, e a busca pela terra emerge. É importante entender que desde antes da emergência da luta, e até os dias atuais, os integrantes desse grupo residem diferentes locais ao longo das margens do rio Arapuim e locais próximos, pois não possuem terras, são trabalhadores rurais em fazendas da região, prestam outros serviços na cidade, ou vivem em terras de parentes cedidas para moradia. É assim que a necessidade de buscar a terra se apresenta.

No entanto, após a identificação da primeira fazenda pelo grupo, uma dificuldade se apresenta, e os Nativos se deparam com a impossibilidade de continuidade dado ao fato da área estar sendo negociada com o Instituto Nacional de Colonização e Reforma Agrária (Incra) e por outras comunidades. A luta continua, e uma segunda fazenda é identificada, a fazenda Torta, localizada na Grande Fazenda Morro Preto, no município de São João da Ponte, com divisa com o município de Verdelândia no Norte de Minas Gerais.

\footnotetext{
Sônia Nicolau dos Santos (1985).

7 Para mais informações sobre lutas territoriais de comunidades quilombolas na região do Norte de Minas Gerais, acessar estudo de João Batista de Almeida Costa (1999) e Aderval Costa Filho (2008).
} 
É esse processo que buscamos compreender. Pois, ao longo do caminho, a luta ganha novo formato e a identidade camponesa passa por uma releitura, construindo um processo de reflexão acerca da constituição do grupo por meio de seus antepassados, sua ancestralidade negra, se reconhecendo como "descendentes de escravos que se refugiaram às margens do rio Arapuim"8 nos municípios de Verdelândia, Varzelândia e São João da Ponte, no Norte de Minas Gerais. São essas transformações que possibilita o acionamento e releitura da identidade quilombola no ano de 2007 pelos Nativos do Arapuim, originando a primeira associação quilombola do município de Verdelândia, formada pela união das comunidades de Boa Vista, Limeira, Boa Sorte e Vista Alegre.

O objetivo deste estudo é focar a luta por reconhecimento do território e $\mathrm{o}$ ato de violência sofrido pelos Nativos, chamado pelos mesmos como "Novo massacre de Cachoeirinha", ocorrido no ano de 2014. Para alcançá-lo, utilizamos as informações obtidas ao longo da pesquisa para construção da dissertação de mestrado, como o trabalho de campo, entrevistas livres e observações participantes. O exame histórico e documental constitui um instrumento analítico e permite construir o que entendemos por "Três tempos de luta" e "Cinco atos de luta”. A constituição de tempos e atos não implica em separação dos acontecimentos, mas na diferenciação deles, para estabelecermos a relação existente entre os processos históricos. Desse modo, o objetivo aqui proposto se delimita no "Terceiro tempo de Luta" e mais especificamente, no "Quarto ato de luta" e "Quinto ato de luta". A figura 1, a presentado a seguir, sintetiza e explica a construção dos tempos e atos de luta.

O primeiro e segundo tempos de luta foram pensados a partir de estudos desenvolvidos por outros autores, Santos (1985) e Monção (2009), respectivamente. O terceiro tempo de luta é construído a partir dos meus estudos para monografia de graduação e dissertação de mestrado (SILVA, 2015; 2017), referente ao processo de reemergência da luta por terra em Verdelândia, e em seguida, o processo de territorialização da luta agrária, o acionamento da

\footnotetext{
Abaixo-assinado realizada pela Associação Quilombola das Comunidades Nativas do Arapuim (AQCNARA) e encaminhada ao Ministério Público Federal do Estado de Minas Gerais no dia 29 de abril de 2015, tendo como o objetivo denunciar e relatar o Massacre sofrido no dia 19 de janeiro de 2014.
} 
identidade quilombola no município, o que se configura como algo inédito, uma vez que é a primeira associação quilombola do município.

É importante ressaltar que o acionamento da identidade para reconhecimento do território é algo legítimo, tendo em vista que esse processo envolve "momentos de transição" em que novas estratégias são criadas para organização das demandas do grupo, tornando "saberes práticos um vigoroso instrumento jurídico-formal" por meio do ato de "reconhecer suas identidades coletivas e mobilizar forças em torno delas" (ALMEIDA, 2008, p. 17).

Figura 1: Tempos e atos de luta.

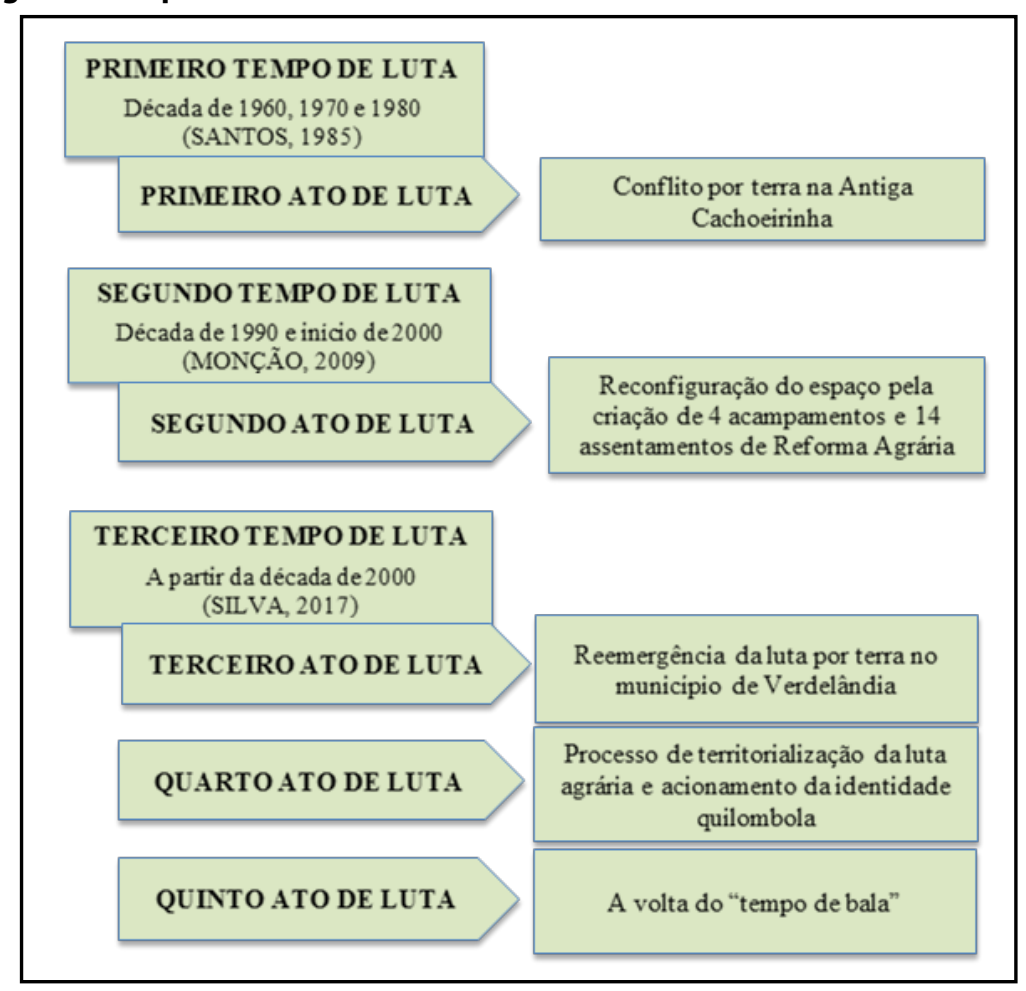

Fonte: Construído pela autora para o presente artigo e a partir do quadro original presente na dissertação de mestrado (SILVA, 2017). 


\section{A FORMAÇÃO DO POVOADO DE CACHOEIRINHA, O MASSACRE DOS ANTIGOS POSSEIROS E A CONFIGURAÇÃO DO NOVO CENÁRIO FUNDIÁRIO}

De forma breve, falaremos da formação do povoado de Cachoeirinha que ocorre no período da escravidão, segundo Santos (1985), e está relacionado com o "desenvolvimento" do Norte de Minas Gerais. Com a resistência dos negros, muitos fogem e se instalam no Vale da Jaíba ${ }^{10}$ que também é habitada por índios. A partir de 1926, o início da construção da estrada de ferro que conectava as cidades de Montes Claros-MG/Belo Horizonte-MG/ Rio de Janeiro-RJ, prolongada até a cidade de Monte Azul, auxiliou na formação de demais povoados em torno das estradas (SANTOS, 1985, p. 16).

Embora não exista registros oficiais sobre o período de formação do povoado de Cachoeirinha, segundo entrevistas realizadas por Santos (1985, p. 20), "pode-se calcular, no entanto, que o povoado tenha surgido no início dos anos 40". A primeira geração de posseiros é constituída por trabalhadores da linha férrea, na construção da ferrovia na cidade de Janaúba, e após 1940 ocorre a integração entre antigos (índios e negros) e novos moradores do povoado. Com a conclusão da linha férrea Salvador-BA/Belo Horizonte-MG no ano de 1946, o fluxo migratório se intensifica de acordo com Santos (1985, p. 25), formando a segunda geração de posseiros, ou seja, migrantes.

Vários são os acontecimentos que contribuem para o massacre dos posseiros na década de 1960, um deles é a "divisão judicial da fazenda Arapuã, município de Varzelândia, quando houve a separação de duas glebas, a ausentes incertos e desconhecidos" (SANTOS, 1985, p. 51), descrita em documento do ano de 1930. Após a venda de partes da fazenda a outras pessoas, dois compradores podem ser destacados, os senhores Sebastião Alves da Silva e

\footnotetext{
O desenvolvimento referido pelo presente trabalho é o processo de industrialização modernização da agropecuária regional e instalação de monoculturas de eucalipto e pinus, ocorrido, principalmente, a partir de meados do século XX. Em 1965 o Norte de Minas Gerais passou a integrar a área de abrangência da Superintendência de Desenvolvimento do Nordeste - Sudene (OLIVEIRA et al., 2000).

${ }_{10}$ De acordo com Costa (2012, p. 194) "à vegetação que cobria o vale foi dada a denominação de mata da jahyba. Tal denominação, em tupi-guarani, realizada pelos membros da bandeira que ocupou a região no século XVII, conhecida atualmente como Norte de Minas, expressava as condições endêmicas da área”.
} 
Manoelito Maciel de Salles que compram cerca de 968 hectares, equivalente a 200 alqueires mineiros, mas expulsam famílias e tomam posse de 2 mil alqueires. Em seguida, em 1964, com o apoio do advogado e Coronel Georgino Jorge de Souza, passam então a reivindicar aproximadamente 6.400 hectares. É nesse momento que emerge o conflito de Cachoeirinha, seguido do massacre dos posseiros em dois despejos específicos.

No primeiro despejo, ocorrido em 14 de setembro de 1964 e baseado em um mandado de desapropriação de terras, emitido pelo Juiz de Direito da cidade de São João da Ponte, 32 famílias são expulsas por meio de atos violentos e apoio de militares (SANTOS, 1985, p. 48). Embora o primeiro despejo não tenha registro de mortes, ele marca o início da luta, seguido de outros despejos, registrados com a morte de 64 crianças e o assassinato de um dos líderes dos camponeses, descritos ao longo do texto, com a testemunha das outras expulsões. Esse momento histórico é marcado pela criação do Estatuto do Trabalhador Rural e, no mesmo, o Estatuto da Terra (Lei no 4.504), que de acordo com o Art. 1 "regula os direitos e obrigações concernentes aos bens imóveis rurais, para os fins de execução da Reforma Agrária e promoção da Política Agrícola" (BRASIL, 1964). É importante considerar que "o Estatuto da Terra reconheceu a existência de uma questão agrária, de interesses conflitantes dentro daquilo que, até então, era tratado como um todo indivisível, a agricultura ou, já convertida ao jargão corporativista, a classe rural” (PALMEIRA, 1989, p. 101).

O segundo despejo ocorreu no ano de 1967, quando cerca de 212 famílias são expulsas e desterritorializadas, outro que também procedeu de forma agressiva com a prática de vários atos de violência como queima de casas, plantações, morte de animais, proibição de pesca, retirada de lenha, ameaças e agressões físicas (SANTOS, 1985, p. 56).

Além das violações de direitos humanos houve a morte de 64 crianças no ano de 1971, atribuída pelos posseiros expulsos ao processo violento de desapropriação. As famílias se abrigavam em quintal de parentes e amigos, embaixo de árvores, sem uma moradia fixa e segura que, juntamente com a falta de alimentos, provocou a morte das crianças pela exposição ao frio e à 
fome. Essa situação de vulnerabilidade é relatada por Santos (1985, p. 61), que também fala da enchente no Rio Verde Grande, agravante da condição dos posseiros despejados. O assassinato da principal liderança do movimento em 1975, senhor Martinho Fagundes de Lisboa, foi outro trágico momento vivenciado pelos camponeses, que se deparavam com o cumprimento das ameaças de morte e nenhuma justiça sendo feita.

É importante ressaltar que o termo "massacre" é utilizado nos depoimentos dos próprios posseiros expulsos na década de 1960, pois, diante da vivência das práticas de violação de direitos que contribuíram diretamente com a morte das 64 crianças e o assassinato de um dos líderes do movimento, os camponeses relatam que foram vítimas de um massacre legitimado pelo governo da época (SANTOS, 1985). Esses relatos, ao serem divulgados, levam o conflito ao conhecimento de pesquisadores e movimentos sociais que se inserem na luta e se apropriam do termo utilizado pelos camponeses, denominando o ocorrido como "Massacre de Cachoeirinha", sendo assim conhecido em toda região.

Depois de dezenove anos de luta e vários ocorridos trágicos, o ano de 1983 é marcado pelo anúncio do então governador de Minas Gerais, Tancredo Neves, do Decreto $n^{\circ} 23080$, que entendia como "utilidade pública, para desapropriação de pleno domínio, áreas de terras e benfeitorias situadas do Distrito de Cachoeirinha, município de Varzelândia" (apud SANTOS, 1985, p. 113). Esse é o primeiro momento real de possibilidade de resolução do conflito vivenciado pelos posseiros, representando uma conquista, uma vitória na luta pela terra. Ainda assim, segundo Monção (2009), a insuficiência da terra demarcada para reforma agrária gera dificuldades para decisão e seleção de famílias a serem assentadas. No entanto, 55 famílias são instaladas na área e cria o assentamento União. Em 1983, uma segunda área para desapropriação funda o assentamento Caitité, com remanescente de Cachoeirinha.

Após a criação dos dois primeiros acampamentos, a nova configuração agrária do município ocorre a partir da década de 1990 onde, até o ano de 2007, cerca de 11 assentamentos e 4 acampamentos de reforma agrária são constituídos. O quadro 1 apresenta a reconfiguração agrária do município. 
Quadro 1: assentamentos e acampamentos de Verdelândia.

\begin{tabular}{|c|c|c|}
\hline Ano de Criação & Assentamento & Acampamento \\
\hline \multirow{2}{*}{1983} & União & - \\
\cline { 2 - 3 } & Caitité & - \\
\hline \multirow{2}{*}{1989} & Boa Esperança & - \\
\cline { 2 - 3 } & Arapuá & - \\
\cline { 2 - 3 } & Arapuim & - \\
\hline \multirow{2}{*}{1999} & Verde Minas & Santa Clara \\
\hline \multirow{2}{*}{2000} & Betânia & - Verde Água \\
\hline \multirow{2}{*}{2002} & Serrana & Vitória \\
\hline & - & - \\
\hline \multirow{2}{*}{} & Bom Jardim & - \\
\hline \multirow{2}{*}{2003} & Lagoinha & - \\
\hline \multirow{2}{*}{2004} & Volta da Serra & - \\
\hline \multirow{2}{*}{2007} & Bom Sucesso & - \\
\hline & Nova Esperança & Vista Alegre \\
\hline
\end{tabular}

Fonte: SILVA (2015), elaborado a partir de MONÇÃO (2009).

Após a criação dos primeiros assentamentos, de acordo com Santos (1985), o povoado de Cachoeirinha é renomeado por fazendeiros, sendo chamado de Railândia. Em seguida, em 1995, através da Lei Estadual no 12030, de 22/12/1995, o local é emancipado e se torna o município Verdelândia.

Além do histórico agrário do município, é necessário refletirmos sobre o debate teórico da reforma agrária, pois a criação de assentamentos, na perspectiva de Medeiros e Leite (1998, p. 161), “acarreta a introdução de novos elementos e agentes que ocasionam alterações nas relações de poder”. Essa modificação nas estruturas de poder ocorre pela efetivação dos assentamentos que, segundo Martins (2004, p. 102), pode ser entendido como "forma da redistribuição de terra, que é em que consiste, no essencial, qualquer reforma agrária”. Nesse debate, entenderemos a reforma agrária como um processo que 
representa "uma série ordenada de atos sucessivos e, como tal, implica uma ideia de tempo e de espaço" (SILVA, 1971, p. 38). O que enfatizamos aqui é que a demanda por terra e a regularização desta implica na construção de novas demandas e na reconfiguração dos agentes sociais de luta, que se posicionam em uma luta por justiça e "direitos antes não reconhecidos" (MEDEIROS; LEITE, 1998, p. 165).

Essa modificação de estruturas pela reforma agrária é evidenciada na reconfiguração do cenário agrário de Verdelândia, motivando a continuidade da luta pela terra no município. Ainda assim, para que a reforma agrária possa ocorrer, é necessário a legitimação da luta, que ocorre não apenas pelo histórico de luta, como é o caso dos descendentes dos antigos posseiros de Cachoeirinha, mas também no campo jurídico. Desse modo, podemos entender como base legitimadora a Lei no 4.504, de 30 de novembro de 1964 da Constituição Federal, que regula os direitos e obrigações concernentes aos bens imóveis rurais, para os fins de execução da Reforma Agrária e promoção da Política Agrícola.

Ainda reconhecendo a importância do campo jurídico, é por meio das vivências dos grupos que a construção da luta ocorre, tendo como essencial o acionamento da identidade. No caso dos Nativos do Arapuim, a identidade se reconfigura ao longo do processo, se iniciando com a identificação dos modos de vida camponês, e depois como quilombolas. Essa reconfiguração da identidade é legítima, como argumentado por Little (2002). Com a possibilidade de reconhecimento e titulação das terras de remanescentes de quilombo, a identidade quilombola é acionada, sendo para os pesquisadores, entre outras coisas, uma categoria de análise, e para o Estado uma categoria jurídica. No entanto, para os Nativos do Arapuim, é uma forma de dialogar dentro do campo de debate proposto pelo Estado e com a categoria reconhecida e legitimada por este.

O que o presente trabalho busca refletir é que o acionamento da identidade é legítimo, para além de uma estratégia de luta utilizada pelos povos tradicionais para que o Estado reconheça os seus direitos. É um processo que implica cultura, modos de vida, ancestralidade, história de luta e diferenciação 
do grupo diante dos demais grupos sociais. No caso dos Nativos do Arapuim é interessante observar que, ao se reconhecerem como quilombolas, não abandonam o termo Nativos, mas se apropriam de uma nova categoria, reconhecida pelo Estado. Dessa forma, esses agentes unem a categoria de nativo (categoria nativa para esses povos, ou seja, uma categoria interna do grupo) com a nova categoria, quilombola (categoria retirada do campo jurídico do Estado, ou seja, uma categoria externa), tendo como objetivo dialogar como o Estado, formando assim o grupo social dos quilombolas Nativos do Arapuim. É esse processo de reconstrução da identidade que buscaremos compreender a partir das informações obtidas em campo.

Como destacado anteriormente, antes da década de 1960, período em que ocorre o Massacre de Cachoeirinha, há um contexto nacional de privação da terra. Desse modo, embora reconhecendo o histórico agrário, a luta por terra e território vivenciada pelos grupos sociais do município de Verdelândia, é delimitada aqui, a partir da década de 1960. Destacamos ainda a formação de uma geração de posseiros descendentes de escravos, e outra geração composta por migrantes de outras regiões e que sofreram expropriações.

A partir do massacre, a reconfiguração do espaço agrário ocorre com a formação de novos assentamentos e acampamentos de reforma agrária. Entre esses processos de formação, a luta por terra continuou, exemplificada aqui pela realidade dos Nativos do Arapuim. Nesse caso, entendendo os Nativos enquanto descendentes dos posseiros da antiga Cachoeirinha, reforçamos que o início efetivo da luta desse grupo específico ocorre no ano de 2004, quando a identidade camponesa é acionada pelo grupo, a herança histórica de luta é reafirmada e a busca pela terra emerge. É importante entender que antes da emergência da luta, e até em dias atuais, os Nativos estão em diferentes locais ao longo das margens do rio Arapuim, pois não possuem terras e são trabalhadores rurais em fazendas da região, ou prestam serviços na cidade e vivem em terras de parentes, cedidas para moradia. É assim que a necessidade de buscar a terra se apresenta.

O ano de 2004 é marcado pela identificação, por parte dos Nativos, da "fazenda Paulo Macedo", como é conhecida na região. A ocupação é feita por 
famílias, mas é desfeita logo em seguida devido à negociação entre o Incra e outro grupo da região pela mesma porção de terra que ocorreu concomitante. Em seguida, os Nativos identificam a fazenda Torta, que estaria à venda, localizada dentro da Grande Fazenda Morro Preto. A informação é confirmada pelo proprietário, o que motiva o grupo se encaminhar até o Incra para negociação e a primeira ocupação em 2007. No entanto, com a fazenda ocupada, ocorre a primeira reunião entre os Nativos e o Incra para tratar da área identificada, e a informação obtida é de que se tratava de área reconhecida pela Fundação Cultural Palmares (FCP) como remanescente de quilombo, impossibilitando a destinação para reforma agrária, e mostrando um novo caminho de luta, até então desconhecido pelo grupo, o caminho quilombola.

$\mathrm{O}$ reconhecimento da área pela $\mathrm{FCP}$ ocorre no processo de reivindicação de outro território quilombola, o Brejo dos Crioulos, primeira comunidade do Norte de Minas Gerais a conquistar seu reconhecimento e território, localizado no município de Varzelândia, divisa com Verdelândia. No momento de luta do Brejo dos Crioulos, a FCP, por meio de pesquisas antropológicas na região, identifica áreas de remanescentes de quilombo para além da área reivindicada pelo Brejo dos Crioulos. Segundo os Nativos do Arapuim, no ano de 2003, quando a FCP visitou a região para o processo de formação do Brejo dos Crioulos, "o levantamento mostrou que a gente é quilombola né, é do quilombo... e a gente tem um certificado, Boa Vistinha e Limeira tem o certificado da Fundação Palmares"11. Mas, ainda assim, a identidade quilombola não foi acionada, pois, segundo o grupo, não entendiam o que isso significava, o que os impulsionou a lutar via reforma agrária, única forma que até então conheciam de acessar a terra.

O foco deste estudo é esse processo de reconfiguração da luta e, em seguida, o novo massacre dos Nativos. O uso do termo "novo massacre" é utilizada pelos próprios Nativos do Arapuim, pois estes fazem associação ao despejo violento e agressivo sofrido no ano de 2017 com os despejos da década de 1960. Esse processo de reconfiguração da luta se apresenta como processo de "redefinição dos instrumentos da ação fundiária oficial”. (ALMEIDA, 2008, p. 18).

\footnotetext{
${ }_{11}$ Entrevistado 1. Nativo do Arapuim. Entrevista realizada 08/01/17. Pesquisa de Mestrado (SILVA, 2017).
} 


\section{A TERRITORIALIZAÇÃO DA LUTA AGRÁRIA, 0 ACIONAMENTO DA IDENTIDADE QUILOMBOLA E O "NOVO MASSACRE" DOS NATIVOS}

O primeiro elemento de ressignificação da luta é a criação da Associação Quilombola das Comunidades Nativas do Arapuim (AQCNARA), no dia 11 de novembro de 2007, formada por aproximadamente 300 famílias, composta pela união das famílias que estavam acampadas na Fazenda Torta, mas que, após serem expulsas, voltam a residir em terras de parentes nas comunidades de Boa Vista, Limeira, Boa Sorte e Vista Alegre. Esse grupo social é formado por "descendentes de escravos que se refugiaram às margens do rio Arapuim, nos municípios de Verdelândia (antiga Cachoeirinha), Varzelândia e São João da Ponte, no Norte de Minas Gerais"12. O grupo social dos Nativos afirmam em seus depoimentos que a região foi formada pelos seus antepassados, escravos, vindos do sul da Bahia que resistiam e fugiam da escravidão; construindo uma comunidade às margens do rio Arapuim, onde plantavam e reproduziam seus modos de vida, por mais de duzentos anos, mas com o massacre de cachoeirinha na década de 1960 foram retirados do local, habitando áreas em torno.

É por meio das mudanças no cenário de luta que os Nativos promovem uma reflexão sobre seus antepassados e seu pertencimento local. Mudanças que são essenciais no processo (impossibilidade de ocupação da primeira fazenda identificada; identificação da segunda fazenda, Torta/Morro Preto; impossibilidade de reforma agrária para a fazenda Torta; esclarecimento sobre outras possibilidades de acesso à terra; reflexão sobre atuação da FCP na região; e consciência da posse de certificado de quilombola).

É necessário ressaltar que a luta por terra implica mais que reprodução econômica e de produção, é reflexo de uma estrutura concentrada e desigual nos modos de apropriação dos recursos. Para Martins (2004) é um ato legítimo, é uma forma de legitimar a posse, fragmentando e desconstruindo um

\footnotetext{
12 Abaixo-assinado realizado pela AQCNARA e encaminhada ao Ministério Público Federal do Estado de Minas Gerais no dia 29 de abril de 2015, tendo como o objetivo denunciar e relatar o Massacre sofrido no dia 19 de janeiro de 2014 .
} 
sistema em que a terra é concentrada, possibilitando o acionamento da identidade e busca por direitos.

No ano de 2010 ocorre a primeira expulsão dos Nativos, associado ao relato de uma possível venda da fazenda Torta que até então era ocupada pelo grupo, mas são retirados pelo possível comprador, conhecido na região como “Joãozinho Diniz". Após expulsas, as famílias retornam para suas antigas ocupações, moradias em terras de parentes próximas à região do rio Arapuim. De acordo com as informações obtidas pelos Nativos, a venda é feita em 2004. No entanto, de acordo com o contrato de compra e venda, o qual tivemos acesso, intitulado "Instrumento particular de promessa de compra e venda de imóvel rural”, a negociação é assinada na data de 14 de fevereiro de 2012, com a assinatura do sr. Juarez Geraldo Diniz (administrador do imóvel rural) e Tania Maria Diniz Andrade (promitente vendedora e legítima proprietária do imóvel) e o sr. João Evangelista Dias (promissário comprador).

No ano de 2012 ocorre outra ocupação e em 2013 uma nova expulsão, por meio de uma Liminar Judicial. De acordo com os Nativos, não ocorreu apenas o despejo, mas a destruição de toda a plantação feita. Em 2014 a terra é ocupada novamente mas no dia seguinte, 19 de janeiro de 2014, os Nativos se deparam com a chegada de dez homens em uma caminhonete, encapuzados e armados que atiram contra o acampamento, atingindo algumas pessoas, agredindo fisicamente aqueles que estavam no local, derrubaram as casas improvisadas, configurando o que os Nativos denominaram de "novo massacre". Foi uma ação de violência extrema contra homens, mulheres, idosos e crianças que é exemplo das várias violações de direitos vivenciadas pelos povos e comunidades tradicionais; mostrando a complexidade e dificuldade das diferentes lutas pelo reconhecimento do território.

A criminalização da luta dos povos é um mecanismo utilizado por latifundiários para justificar as agressões e violações de direitos que busca legitimar as práticas agressivas, entendidas pelos grandes proprietários de terra como modo de resolução de conflito. Segundo relatos de alguns dos Nativos do Arapuim, os jagunços "botou [colocou] gado dentro da roça e comeu tudo[...] 
tacou [colocou] fogo no povo e nas casas"13. Isso aconteceu "porque o fazendeiro chegou aqui e queria tirar o povo de tudo quanto é jeito"14.

"Ai eles foram lá e bateram no pessoal, atirou em gente, bateram em criança, machucou as mulheres e aquelas coisa lá, foi uma coisa muito feia né, muito assim... o pessoal desorientou, ficou todo mundo desorientado, sem saber o que fazia, gente atirado, gente ensanguentado, gente cortado a cabeça, gente... né... Mulher lá desmaiada pelo chão, alguém com o pescoço queimado de espingarda 12 que atirou para cima e esquentou o cano lá e acabou queimando os pescoços. [...]. As crianças que esteve lá ficou com traumas né, até hoje tem crianças com trauma ainda [...]" (Entrevistado 1. Nativo do Arapuim. Entrevista realizada 08/01/17).

Embora autoidentificado como quilombola, é importante considerar que a prática de ocupação exercida pelos Nativos é uma estratégia do Movimento Sem Terra (MST) que, por meio da identificação de áreas improdutivas, promovem ocupação como forma de pressionar as instituições responsáveis pela efetivação da reforma agrária. No entanto, a ocupação feita pelos Nativos não se pauta na função social da terra, tendo como base elementos de produtividade, mas se fundamenta na relação de pertencimento e vínculos históricos com o território, entre eles a ancestralidade negra. É necessário ressaltar ainda que a condição atual dos Nativos e de outros grupos sociais do município de Verdelândia como desterritorializados ocorre pela perda de suas terras na década de 1960. Mesmo com a configuração de assentamentos e acampamentos na região anos após o massacre, a quantidade é insuficiente para todas as famílias desterritorializadas no processo, implicando em moradias feitas em terras de parentes, com plantações e criações feitas por famílias extensas, que compartilham a mesma parcela pequena de terra.

No dia 29 de abril de 2015, como forma de denúncia do ato de violência, os Nativos encaminham um abaixo-assinado em nome da associação quilombola para o Ministério Público Federal do Estado de Minas Gerais.

\footnotetext{
13 Entrevistado 4. Nativo do Arapuim. Entrevista realizada 28/02/17. Pesquisa de Mestrado (SILVA, 2017).

${ }_{14}$ Entrevistado 3. Nativo do Arapuim. Entrevista realizada 28/02/17. Pesquisa de Mestrado (SILVA, 2017).
} 
O medo de recorrência da violência é uma preocupação dos Nativos, exposta no texto do abaixo-assinado, tendo em vista que a luta continua e a resistência é real, um dos depoimentos enfatiza que "jamais o pessoal vai abrir mão, porque é aonde que eles derramaram sangue, aonde que eles sonham em ter um pedaço de terra, uma terra que eles viram a família crescendo né, então eles não vão abrir mão"15.

Na Figura 2, à esquerda, há uma fotografia do local onde o massacre ocorreu, com resíduos das casas de lona derrubadas e queimadas e, à direita, a imagem do cruzeiro, que representa símbolo de resistência e memória do grupo, colocado no local após o ocorrido.

Figura 2: casas queimadas e cruzeiro no local do massacre sofrido pelos Nativos.
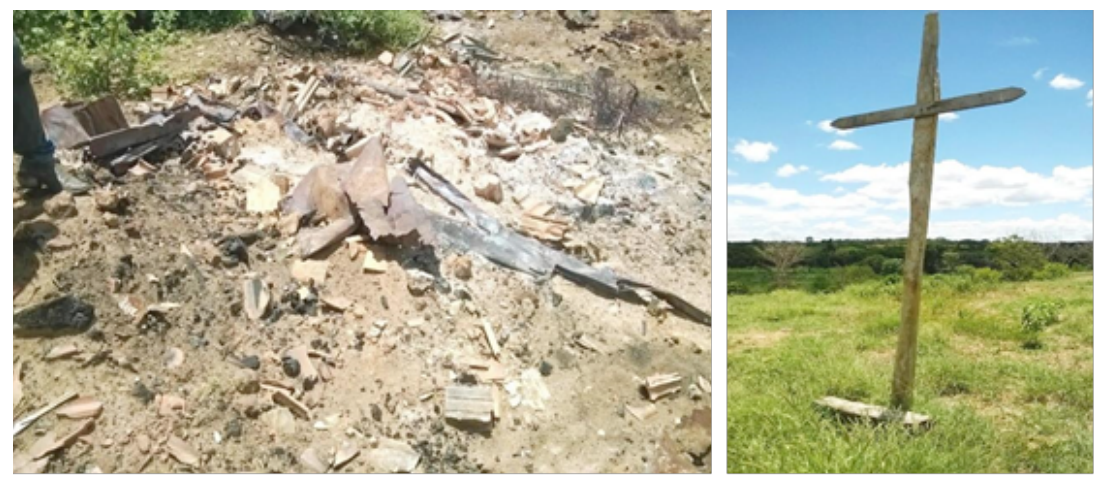

Fonte: SILVA (2017).

É importante ressaltar que, após o massacre ocorrido, foi aberta uma investigação, com perícia realizada no local e apresentação de fotos dos ferimentos dos Nativos no laudo médico em anexo ao Processo no $0002277-$ 35.2014.8.13.0624/0624.14.000227-7 Mandado: 2. Após a abertura do processo, o contrato de compra e venda foi cancelado pelos promitentes vendedores e legítimos proprietários do imóvel, retornando a posse da Fazenda Torta/Morro

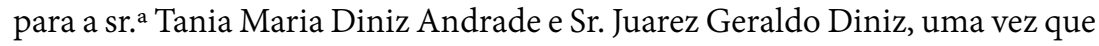
o processo de compra e venda não havia sido concluído.

\footnotetext{
15 Entrevistado 1. Nativo do Arapuim. Entrevista realizada 08/01/17. Pesquisa de Mestrado (SILVA, 2017).
} 
Após o "novo massacre", os Nativos se estabelecem no acampamento Santa Fé, tornando o local espaço para reuniões e encontros do grupo com as entidades de apoio. A ocupação não é apenas necessidade, mas uma estratégia para se manter ao lado da área reivindicada. Mesmo com a expulsão os Nativos permanecem próximos ao local, e uma das estratégias utilizadas é a criação de um acampamento, chamado de Santa Fé, às margens do rio Arapuim, dentro do território do município de Verdelândia. Na Figura 3 é exposto o mapa que apresenta a área reivindicada e a área de acampamento dos Nativos que é criada em 2014.

\section{Figura 3: mapa das áreas ocupada e reivindicada pelos Nativos do Arapuim.}

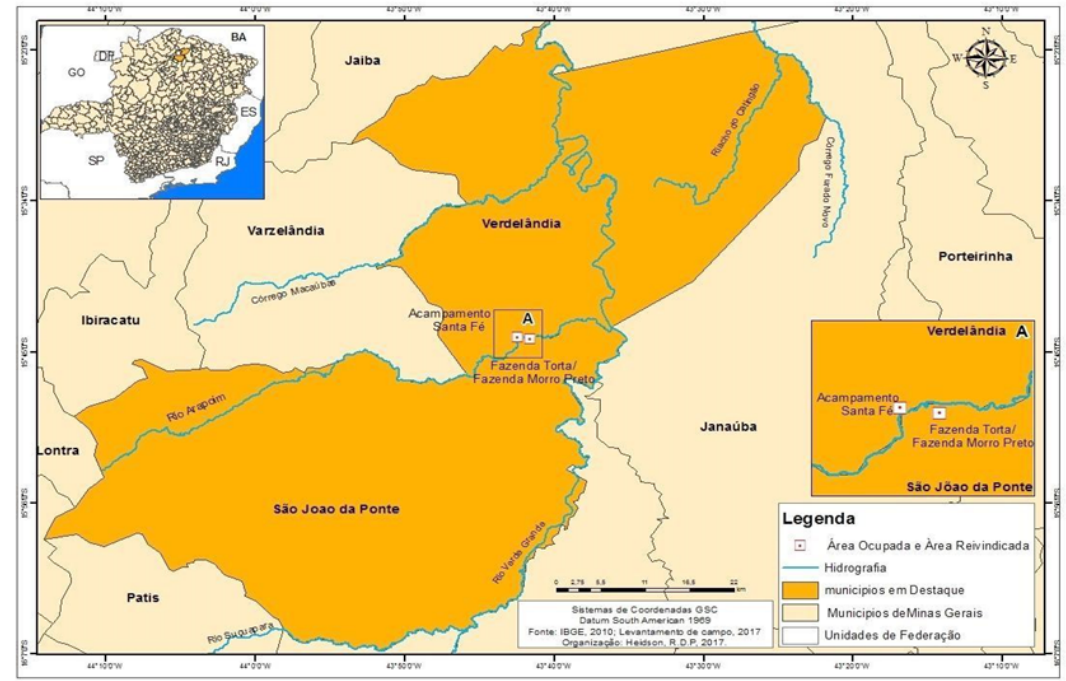

Fonte: SILVA, 2017.

O atual acampamento Santa Fé, é o local onde algumas famílias dos Nativos habitam, outras se encontram em locais anteriores, como fazendas em que trabalham ou moradias cedidas em terras de parentes. O acampamento possui uma área pequena para instalação de todas as famílias da associação quilombola e se localiza ao lado da estrada de acesso entre os municípios de Verdelândia ao município de Varzelândia. O local não possui água e eletricidade, as casas são feitas de lonas, improvisadas, e não possuem banheiros. 
De acordo com o advogado dos Nativos, Sr. André Alves, a área do acampamento também é reivindicada pelos Nativos.

Figura 4: acampamento Santa Fé e estrada Acampamento Santa Fé/Fazenda Torta feita na parte seca do rio.
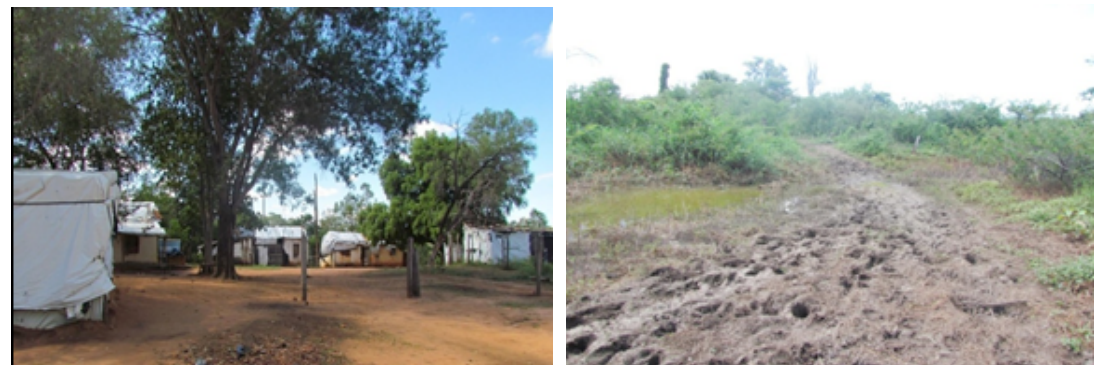

Fonte: SILVA, 2017.

Uma parte do local do acampamento é destinada para uma pequena plantação, como milho, feijão, abóbora, mandioca, hortaliças, entre outros. A produção é destinada para consumo das famílias no local, auxiliando na alimentação, tendo em vista a dificuldade de manutenção das famílias, já que muitos não possuem emprego fixo, outros são aposentados e alguns contam com auxílio de programa social como o Bolsa Família.

\section{RECONSTRUÇÃO DA LUTA E A BUSCA PELO RECONHECIMENTO DO TERRITÓRIO QUILOMBOLA}

A partir da apresentação de dados obtidos no campo para contextualização do cenário de luta, é necessário estabelecermos um diálogo com teóricos no âmbito do debate. Um dos elementos essenciais para a territorialização da luta é o acionamento da identidade e da cultura do grupo. A transição de uma luta por terra para território envolve os modos de vida e cultura do grupo, pois, segundo Cunha (2009, p. 239), “a cultura não é algo dado, posto, algo dilapidável também, mas sim algo constantemente reinventado, recomposto, investido de novos significados", possuindo dinâmica própria e se tornando uma arma de luta para os mais fracos. 
É com base nesse processo dinâmico que entendemos como legítimo o acionamento da identidade quilombola. No entanto, a legitimidade se efetiva por meio do Estado e de suas categorias jurídicas, por isso enfatizamos que "quilombola" serve como categoria de análise para os pesquisadores, enquanto para o Estado é uma categoria jurídica. Embora pensada como classe, a identidade quilombola ganha sentido na vivência dos povos, sendo uma categoria prática, e evidenciada na criação da AQCNARA. Pensamos essa construção como a "emergência de 'novas' identidades coletivas e dos denominados 'novos movimentos sociais'" (ALMEIDA, 2008, p. 18). A releitura feita pelo grupo consiste numa interpretação que transcende a ideia de terra enquanto local de produção e passa por uma vivência em que ela é percebida como território, local de produção para além da econômica, ressaltando a produção e reprodução dos modos de vida, de saberes tradicionais, e elementos culturais.

O entendimento dos acontecimentos históricos é uma forma de compreender a realidade social em que os Nativos do Arapuim se inserem. Segundo Bourdieu (2004a), a realidade social pode ser entendida como um conjunto de relações invisíveis e definidas umas em relações às outras, envolvendo a noção de campo apresentada por Bourdieu (2004b, p. 22), em que "todo campo, [...], é um campo de forças e um campo de lutas para conservar ou transformar esse campo de forças". No caso dos Nativos, entendemos como tentativa de mudança da estrutura fundiária regional.

A luta e a releitura não é individual, mas coletiva, e conta com o apoio de entidades importantes que fortalecem o processo de compreensão do caminho a ser percorrido, do campo e das categorias jurídicas, do diálogo com o Estado, das possibilidades de acesso e do significado de uma ancestralidade histórica, que passa a ser conhecida pelo grupo. Para a luta dos Nativos, assim como para demais povos tradicionais no Norte de Minas Gerais, o Centro de Agricultura Alternativa do Norte de Minas Gerais (CAA/NM) é uma organização importante e que disponibiliza assessoria jurídica e política, assim como a Articulação Rosalino Gomes de Povos e Comunidades Tradicionais que reúne os povos de luta do Norte de Minas Gerais em uma causa comum. 
É importante informar que o CAA/NM, constituído desde 1985, é "uma organização de agricultores e agricultoras familiares do Norte de Minas Gerais", formada por profissionais de várias áreas de atuação (advogados, agrônomos, antropólogos, sociólogos, biólogos, entre outros), e "por representantes de povos e comunidades tradicionais (geraizeiros/as, catingueiros/as, quilombolas, indígenas, veredeiros/as e vazanteiros/as)". A atuação dessa organização se volta principalmente "em torno da sustentabilidade, da agroecologia e dos direitos dos povos e comunidades tradicionais, tendo como foco a valorização da (agro)biodiversidade e a convivência com os ecossistemas regionais" ${ }^{{ }^{16}}$.

Os direitos reivindicados pelos Nativos, assim como outros povos tradicionais, estão previstos na Constituição Federal de 1988, Art. 215 (Capítulo III Seção II - Da Cultura), $\$ 1^{\circ}$ que prevê que “o Estado protegerá as manifestações das culturas populares, indígenas e afro-brasileiras, e das de outros grupos participantes do processo civilizatório nacional” (BRASIL, 1988, p. 126). A possibilidade de autorreconhecimento, utilizada pelo Nativos, é prevista na Convenção 169 da Organização Internacional do Trabalho - OIT, de junho de 1989, e ratificada pelo Decreto Legislativo no 143 . O fator de autorreconhecimento "reconhece como critério fundamental os elementos de autoidentificação, reforçando, em certa medida, a lógica dos movimentos sociais", e destaca ainda o Art. $2^{\circ}$, que enfatiza que "a consciência de sua identidade indígena ou tribal deverá tida como critério fundamental para determinar os grupos aos quais se aplicam as disposições desta Convenção" (ALMEIDA, 2008, p. 48).

O Decreto Federal $n^{\circ} 4.887$, de 20 de novembro de 2003, também garante os direitos dos povos quilombolas, constando no Art. $2^{\circ}$ o conceito jurídico de comunidades quilombolas, destacando a autoidentificação, relações territoriais, ancestralidade, opressão histórica sofrida e trajetória histórica. Ainda no $\S 1^{\circ}$, temos que a "caracterização dos remanescentes das comunidades dos quilombos será atestada mediante autodefinição da própria comunidade", e no $\$ 2^{\circ}$ "são terras ocupadas por remanescentes das comunidades dos quilombos as utilizadas para a garantia de sua reprodução física, social, econômica e cultural”.

\footnotetext{
${ }_{16}$ Todas as informações em aspas foram retiradas do site oficial do CAA/NM. Disponível em: http://bit.ly/2RlWQaG/. Acesso em: 2 de jul. 2019.
} 
Art. $2^{\circ}$ Consideram-se remanescentes das comunidades dos quilombos, para os fins deste Decreto, os grupos étnico-raciais, segundo critérios de auto-atribuição, com trajetória histórica própria, dotados de relações territoriais específicas, com presunção de ancestralidade negra relacionada com a resistência à opressão histórica sofrida. (BRASIL, 2003)

O Art. 68 do Ato das Disposições Constitucionais Transitórias (ADCT) da CF/88, segundo Figueiredo (2008, p. 4), apresenta que "aos remanescentes das comunidades dos quilombos que estejam ocupando suas terras é reconhecida a propriedade definitiva, devendo o Estado emitir-lhes os títulos respectivos", sendo "a atribuição ao INCRA da competência para a identificação, demarcação e titulação dos territórios quilombolas" atribuição esta resultado do Decreto no 4887, de novembro de 2003 (FIGUEIREDO, 2008, p. 5). De acordo com Figueiredo (2008, p. 7) a interpretação do Art. 68 - ADCT como forma de atender às "demandas de grupos concretos" torna o mesmo artigo "uma possibilidade de acesso ao reconhecimento identitário e à garantia de direitos a um contingente populacional que não encontrara lugar na ordem social competitiva".

Juntamente com a reconfiguração da luta, ocorre a reconstrução dos sujeitos de luta, que são novos, levando em consideração que a reemergência ocorre por meio de uma identidade modificada e ressignificada, sendo o primeiro grupo de Verdelândia a se reconhecer enquanto quilombola. O processo de territorialização se torna um mecanismo e estratégia de luta pelo território de grupos histórico e culturalmente diferenciados. As 'territorialidades específicas', segundo Almeida (2008, p. 29), "podem ser consideradas, portanto, como resultantes de diferentes processos sociais de territorialização e como delimitando dinamicamente terras de pertencimento coletivo que convergem para um território". De acordo com Little (2002, p. 4), a dimensão territorial, "surge quando as terras de um grupo estão sendo invadidas" e "a defesa do território torna-se um elemento unificador".

A relação existente entre a área reivindicada (Fazenda Torta/Morro Preto) e a área ocupada (acampamento Santa Fé), é apresentada no croqui da área (Figura 4), construído pelos Nativos, que traz consigo uma relação de 
presente e passado. Essa articulação ocorre pela forma em que o local reivindicado se apresenta, por meio da descrição com base em memórias e vivências de antepassados e o local de acampamento atual, da vivência em curso. Com base em suas memórias, os Nativos construíram a Figura 5, que foi digitalizada, editada e disponibilizada para análise deste estudo, observamos nela que a percepção do território congrega passado e presente.

Figura 5: croqui do Acampamento Santa Fé e antepassados na Fazenda Torta.

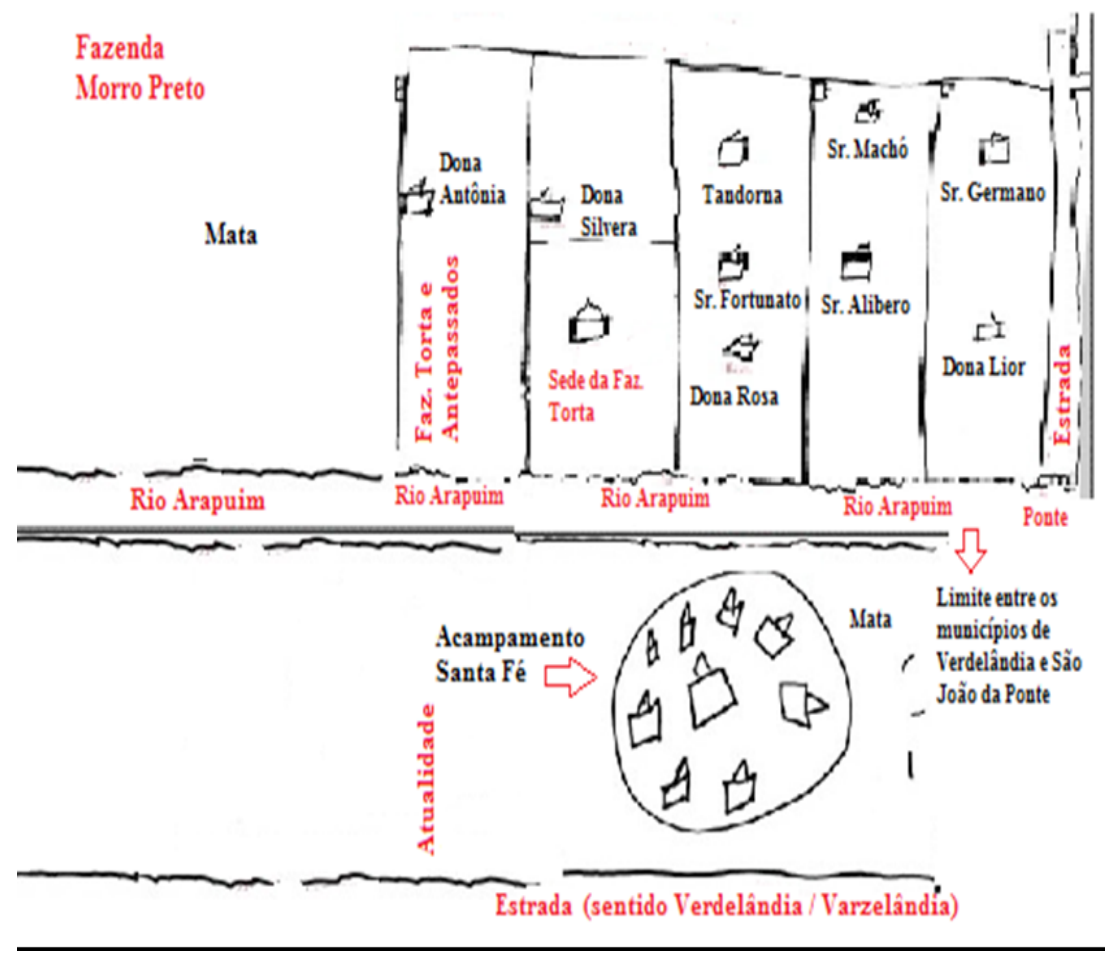

Fonte: croqui desenhado pelos Nativos do Arapuim, editado e digitalizado, presente em Silva (2017).

Para concluirmos os relatos de luta, é importante destacar que a reivindicação do território não se restringe apenas à fazenda Torta, mas outras áreas como a Fazenda Morro preto e acampamento Santa Fé. Algumas partes 
também são de reivindicação das comunidades de Terra Dura e Sete Ladeiras; a possibilidade pensada pelos Nativos do Arapuim é de apropriação das áreas de forma comum, que será pensada de forma coletiva, considerando a existência de relações de parentesco entre esses agentes sociais.

\section{CONSIDERAÇÕES FINAIS}

Para os Nativos do Arapuim a territorialização surge diante de uma impossibilidade de reforma agrária, dado ao fato do território reivindicado ser reconhecido enquanto área de remanescente de quilombo. Esse empecilho também se apresenta como uma oportunidade construída pela releitura e reconstrução da identidade, possibilitando uma reflexão do seu histórico de luta, e entendendo que a reforma agrária não é o único meio de obter o reconhecimento legal de seu território. No entanto, o presente estudo buscou enfatizar o processo de violação de direitos dos Nativos que não são respeitados, mas que estão em pauta na luta, juntamente com o reconhecimento de seu território. A agressão física sofrida pelos Nativos, prática ainda não superada no campo agrário, representa, para aqueles que detêm títulos de grandes extensões de terras, uma forma de resolução dos conflitos agrário, tendo como base o uso da violência e de armas de fogo.

Ganha evidência o grande número de despejos sofridos pelo grupo em todos os locais que seus antepassados ocuparam e, por motivos diversos, tiveram de abandonar em busca de local seguro, como as terras do povoado de Cachoeirinha. A busca pelo direito e legitimidade do histórico de luta representa um reconhecimento das injustiças vivenciadas ao longo dos anos. A resistência é sinal de pertencimento ao local, pois a luta não é unicamente por reprodução material, mas por reprodução dos modos de vida, da própria identidade, assim como da cultura de um povo.

A relação entre os acontecimentos históricos nos permite pensar de forma dialética, os fatos se relacionam e possibilitam a construção de determinadas estruturas, nesse caso, a concentração fundiária que se mantém forte em todo 
território nacional. A luta dos povos e comunidades tradicionais buscam não apenas o acesso aos recursos, mas a desconstrução de estruturas sociais que representam a desigualdade social e assimetria de poder. $\mathrm{O}$ acionamento da identidade tradicional evidencia o posicionamento e resistência de grupos que desejam ser reconhecidos enquanto diferentes, com base em seu histórico de vida e memória coletiva.

Até o presente momento não houve a abertura de nenhum processo no Incra em nome da AQCNARA, pois, segundo a instituição, falta recurso para pagamento de profissionais para desenvolver os procedimentos legais, como, por exemplo, antropólogos para realização de laudos antropológicos. A realidade atual se apresenta como desafiadora, mas a luta se mantém em curso e a resistência dos Nativos conta com o apoio de demais povos tradicionais no Norte de Minas Gerais. A busca pelo território se efetivará, em primeiro momento, com a delimitação do território identificado, reconhecendo a existência dos direitos dos Nativos do Arapuim, que são fundamentados nas dimensões econômica, cultural, política, social e histórica, que guarda resquícios de um massacre que, além de não reparado, é reproduzido.

\section{REFERÊNCIAS BIBLIOGRÁFICAS}

1. Associação Quilombola das Comunidades Nativas do Arapuim (AQCNARA). Abaixo-assinado realizada pela Associação e encaminhada ao Ministério Público Federal do Estado de Minas Gerais. Verdelândia: AQCNARA, 2015.

2. ALMEIDA, Alfredo Wagner Berno de. Terras tradicionalmente ocupadas: processos de territorialização e movimentos sociais. In: ALMEIDA, Alfredo Wagner Berno de. Terras de quilombo, terras de indígenas, "babaçuais livre", "castanhais do povo", faxinais e fundos de pasto: terras tradicionalmente ocupadas. 2 ed. Manaus: PGSCA- Ufam, 2008.

3. BOURDIEU, Pierre. Espaço social e poder simbólico. In: BOURDIEU, Pierre. Coisas Ditas. São Paulo: Brasiliense, 2004a.

4. BOURDIEU, Pierre. Os usos da ciência: por uma sociologia clínica do campo científico. São Paulo: Editora UNESP, 2004b. 
5. BRASIL. Lei no 4.504 de 30 de novembro de 1964. Dispõe sobre o Estatuto da Terra, e dá outras providências. Diário Oficial da União, Poder Legislativo, Brasília, DF, 30 de novembro de 1964, Suplemento, p. 49. Disponível em: http://bit.ly/2R71RDC. Acesso em: 5 dez. 2013.

6. BRASIL. [Constituição (1988)]. Constituição da República Federativa do Brasil: texto constitucional promulgado em 5 de outubro de 1988, com as alterações determinadas pelas Emendas Constitucionais de Revisão nos 1 a 6/94, pelas Emendas Constitucionais nos 1/92 a 91/2016 e pelo Decreto Legislativo no 186/2008. Brasília: Senado Federal, 2016.

7. BRASIL. Decreto $n^{\circ} 4.887$, de 20 de novembro de 2003. Regulamenta o procedimento para identificação, reconhecimento, delimitação, demarcação e titulação das terras ocupadas por remanescentes das comunidades dos quilombos de que trata o art. 68 do Ato das Disposições Constitucionais Transitórias. Diário Oficial da União, Brasília, DF, 20 de novembro de 2003. Disponível em: http://bit.ly/35J6J7q. Acesso em: 2 jul. 2019.

8. BRASIL. Decreto n 6.040 de 7 de fevereiro de 2007. Institui a Política Nacional de Desenvolvimento Sustentável dos Povos e Comunidades Tradicionais Diário Oficial da União, Poder Executivo, Brasília, DF, 7 de fevereiro de 2007. Disponível em: http://bit.ly/2QQxCC1. Acesso em: 5 dez. 2013.

9. COSTA FILHO, Aderval. Os Gorutubanos: territorialização, produção e sociabilidade em um quilombo do centro norte-mineiro. 2008. Tese (Doutorado. em Antropologia Social) - Universidade de Brasília, Brasília/DF, 2008.

10. COSTA, João Batista de Almeida. Do tempo da fartura dos crioulos ao tempo de penúria dos morenos: a identidade através de um rito em Brejo dos Crioulos (MG). 1999. Dissertação (Mestrado em Antropologia Social) - Universidade de Brasília, Brasília/DF, 1999.

11. COSTA, João Batista de Almeida. Processos de territorializações e o deslizamento de conteúdos na etnicidade quilombola em Agreste. Argumentos, Montes Claros, v. 7, n. 1, p. 193-240, 2012.

12. CUNHA, Manuela Carneiro da. Etnicidade: da cultura residual mais irredutível. In: CUNHA, Manuela Carneiro da. Cultura com aspas e outros ensaios. São Paulo: Cosac Naify, 2009. p. 235-244.

13. CUNHA, Manuela Carneiro da. "Cultura" e cultura: conhecimentos tradicionais e direitos intelectuais. In: CUNHA, Manuela Carneiro da. Cultura com aspas e outros ensaios. São Paulo: Cosac Naify, 2009. p. 311-373.

14. LITTLE. Paul Elliot. Territórios sociais e povos tradicionais no Brasil. Anuário Antropológico, Brasília, v. 28, n. 1, p. 251-290, 19 fev. 2018 
15. MARTINS, José de Souza. Reforma agrária: o impossível diálogo. $1^{\text {a }}$ ed. São Paulo: Edusp, 2004.

16. MEDEIROS, Leonilde Servolo de; LEITE, Sérgio Pereira. Perspectiva para a análise das relações entre assentamentos rurais e região. In: SILVA, Francisco Carlos Teixeira da; SANTOS, Raimundo; COSTA, Luís Flávio de Carvalho. Mundo rural e política: ensaios interdisciplinares. Rio de Janeiro: Campus, 1998. p. 152-242.

17. MONÇÃO, Kátia Maria Gomes. As sementes da luta: o conflito agrário de Cachoeirinha - um estudo dos assentamentos e dos acampamentos do município de Verdelândia, Norte de Minas Gerais. 2009. Dissertação (Mestrado em Desenvolvimento Social) - Universidade de Montes Claros, Montes Claros, MG, 2009.

18. OlIVEIRA, Marcos Fábio Martins; RODRIGUES, Luciene; CARDOSO, José Maria Alves et al. Formação social e econômica do Norte de Minas. Montes Claros: Ed. Unimontes, 2000.

19. PAlmeIRA, Moacir. Modernização, Estado e Questão Agrária. In: Estudos Avançados. São Paulo, v. 3, n. 7, p. 87-108, 1989. Disponível em: http://bit.ly/35Pe59u. Acesso em: 05 de Dezembro de 2013.

20. SANTOS, Sônia Nicolau dos. À procura da terra perdida: para uma reconstituição do conflito de Cachoeirinha. 1985. Dissertação (Mestrado em Ciências Políticas) Faculdade de Filosofia e Ciências Humanas. Universidade Federal de Minas Gerais, Belo Horizonte, 1985.

21. SILVA, Greiciele Soares da. A luta por terra e reforma agrária no município de Verdelândia no Norte de Minas Gerais. 2015. Monografia (apresentada ao curso de Ciências Sociais) - Universidade Estadual de Montes Claros (Unimontes), Montes Claros, MG. 2015.

22. SILVA, Greiciele Soares da. Terra e território: a territorialização da luta agrária dos Nativos do Arapuim no Norte de Minas Gerais. 2017. Dissertação (Mestrado em Sociedade, Ambiente e Território) - Universidade Federal de Minas Gerais (UFMG), Montes Claros, MG. 2017.

23. SILVA, José Gomes da. A reforma agrária no Brasil: frustração camponesa ou instrumento de desenvolvimento?. Rio de Janeiro: Zahar Editores, 1971. 